\title{
THE EFFECT OF POLYMER-SURFACTANT ON ACUTE LUNG INJURY INDUCED BY E.COLI IN VENTILATED RATS
}

\author{
X. Gan, H. Li, L. Guo, L. Sun, C. Sun, G. Song \\ Capital Institute of Pediatrics, Beijing, China
}

Objective: The study was to observe the effect of polymer-PS (Curosurf)mixtures on acute lung injury rats with E.coli.

Methods: Adult rats given $3 \mathrm{ml} / \mathrm{kg} 3 \times 109 \mathrm{CFU} / \mathrm{ml}$ E.coli by tracheal, were mechanically ventilated after infection for $24 \sim 36 \mathrm{~h}$. Fifteen minutes later, the animals with ALI $(\mathrm{PaO} 2<20 . \mathrm{kPa})$ were randomly divided into six treatment groups by transtrachea instillation (1) NS group (2) PS group (3) PS+NS group (4) PS+ PEG group (5) PS+ Dextran group (6) PS+ HA group. The blood gas analysis were measured in the pre-or post-treatment during $180 \mathrm{~min}$. At the end, MIP-2 in the right lung lavage fluid were performed.

Result: At 180 min post-treatment, $\mathrm{PaO} 2$ of all PS or PS-polymer treatment groups increased compared with pre-treatment, but they were less than normal control group $(\mathrm{p}<0.01), \mathrm{PaO} 2$ of PS, PS+ Dextran, PS+HA group were singnificantly more than that of the NS group $(p<0.01$ or 0.05$)$ respectively. MIP-2 of lung lavage fluid in all treatment groups were higher than that of normal group $(\mathrm{p}<0.01$ or 0.05$)$. MIP-2 of PS , PS+PEG , PS + Dextran, PS + HA group were less than that of NS group $(p<0.01)$ respectively except $\mathrm{PS}+\mathrm{NS}$ group.

Conclusions: The data suggest that PS, PS+Dextran and PS+HA improved oxygenation function in ventilated rats with ALI induced by E.Coli. and the PS-polymer mixtures seemed more effective in inhibiting MIP-2 than PS in the same dose. Further preclinical studies are required. 